NASA Technical Memorandum 89813

AIAA-87-2112

\title{
Secondary Stream and Excitation Effects on Two-Dimensional Nozzle Plume Characteristics
}

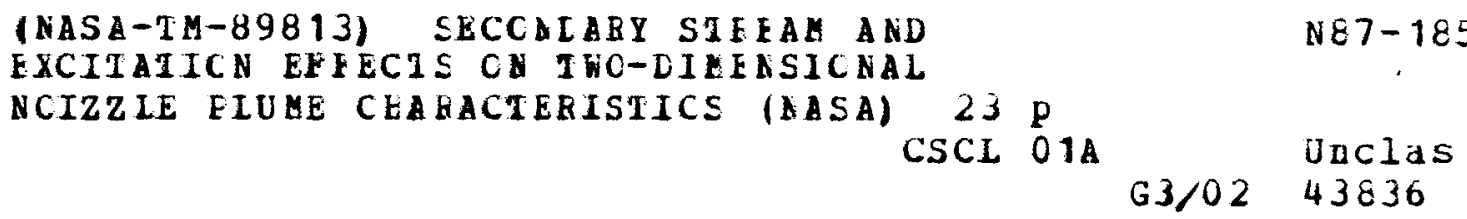

Uwe H. von Glahn

Lewis Research Center

Cleveland, Ohio

Prepared for the

23rd Joint Propulsion Conference

cosponsored by the AIAA, SAE, ASME, and ASEE

San Diego, California, June 29-July 2, 1987

\section{NMSA}


Uwe H. von Glahn

National Aeronautics and Space Administration

Lewis Research Center

Cleveland, Ohio 44135

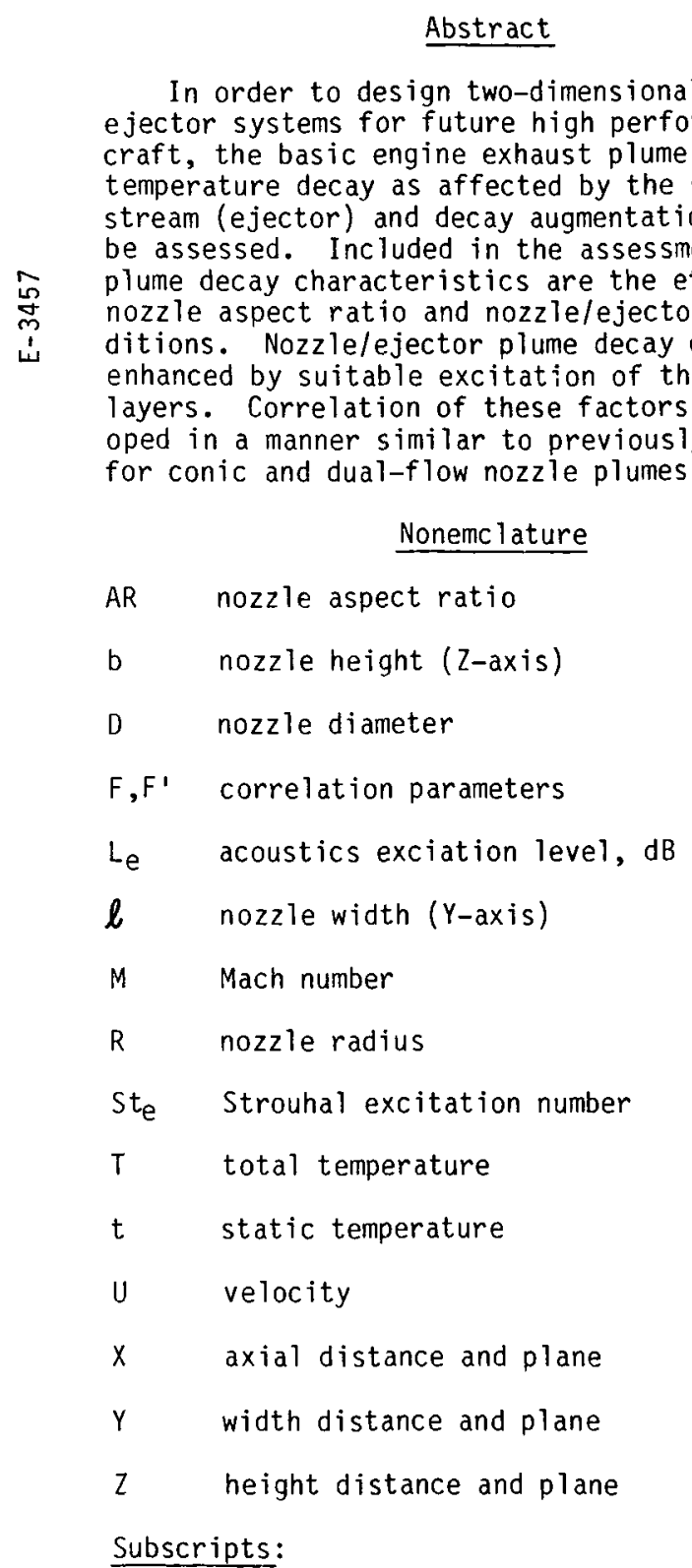

$\begin{array}{ll}\text { a } & \text { ambient } \\ c & \text { centerline } \\ \text { e } & \text { effective } \\ \text { exc } & \text { excited } \\ \text { j } & \text { jet } \\ 0 & \text { secondary stream } \\ \text { R } & \text { radial }\end{array}$

unexc unexcited

z axis direction

0.5 half velocity or half temperature

\section{Introduction}

Propulsion systems for future high performance aircraft will require multipurpose nozzle systems that include thrust reversal and maneuvering features. These multipurpose nozzle requirements can best be achieved with asymmetric nozzles such as two-dimensional nozzle/ejector concepts and the like. In order to minimize the size and weight of such systems, the effect of the secondary stream (ejector flow) and means for increasing the primary stream velocity and temperature decay of the engine exhaust stream must be considered. The latter consideration can include artificial excitation of the engine/ejector flow.

Two-dimensional nozzles inherently provide more rapid plume velocity and temperature decay characteristics than do conic nozzles of equal area and comparable flow conditions. Consequently, two-dimensional nozzles in conjunction with suitable ejectors and plume excitation features can provide a significantly reduced ejector shroud length when compared with conic nozzle/ejector configurations yielding similar decay characteristics.

The secondary or ejector stream causes a reduction in the natural rate of exhaust plume decay, similar to the flight effect on conventional jet exhaust plumes. This causes the plume to stretch in the axial direction and reduces the radial spreading rate (Fig. $1(a)$ ). This in turn causes an increase in ejector shroud length, hence a weight penalty, in order to achieve a desired ejector velocity and/or temperature level.

In order to offset the effect of the secondary stream (ejector flow) on the exhaust nozzle plume, as well as to enhance the basic plume decay, means to augment the rate of plume decay must be included in future nozzle/ejector exhaust systems. Augmentation of the exhaust plume decay rate can be achieved with aero/mechanical, acoustic or thermal means of exciting the large-scale coherent structure of the plume shear layer. Excitation of the plume shear layer reduces the jet core length and increases the spreading rate of the plume (Fig. 1(b)). Results of exciting plume shear layers are independent of the nozzle shape, i.e., shear layers of conic, two-dimensional and dual flow nozzles have all been excited and the results have been similar.

Excitation of plume shear layers has most frequently been achieved with acoustic means, 
although other means may prove to be more practical in the future. In the case of acoustic excitation, the mechanism appears to involve phaselocking of the coherent large-scale structure in the plume shear layer with the acoustic signal. 1 The result is an enhanced mixing of the nozzle exhaust stream with the surrounding ambient (static or moving) medium.1,2

The basic two-dimensional nozzle plume velocity and temperature decay characteristics are presented in Ref. 3. In the present work, the effects on two-dimensional nozzle plumes of secondary streams and artificial excitation of the plume shear layer are discussed and, where appropriate or possible, data correlations are presented.

Two-Dimensional Nozzle Plume Flow Regions

It has generally been accepted that a twodimensional nozzle plume consists of three main regions shown schematically in Fig. 2 and described as follows:

(1) An initial mixing region defined in the literature as the potential core region. In this region, the nozzle plume centerline velocity is essentially constant within the mixing boundaries and with the axial extent of the region being determined by the nozzle half-height, $b / 2$, in the Z-plane.

(2) A transition region aiso defined in the literature as the characteristic decay region. In this region, the velocity decays with increasing axial distance, $x$. At each axial station, the local velocity within the inner mixing boundaries is constant in the nozzle width (Y) plane. The axial extent of the transition region is a function of the nozzle half-width, $\ell / 2$. Note that a square nozzle does not have a transition region because the plume decay is identical in both the $Y$ - and Z-planes,

(3) The final region is defined as the fullymixed or axisymmetric flow region. In this region, the plume peak velocity always occurs at the nozzle centerline.

The plume temperature decay characteristics are similar to those described in the preceding discussion of the plume velocity decay. The axial temperature decay, however, is initiated earlier (closer to the nozzle exit plane) than that of the velocity as shown schematically in Fig. 3. As a consequence, the radial temperature boundary of the plume spreads more rapidly than that of the velocity, also shown in Fig. 3 .

\section{Overall Plume Decay Characteristics}

A schematic sketch of the typical twodimensional nozzle plume centerline decay with axial distance is shown in Fig. 4, together with that for a conic (or square) nozzle plume. It is apparent that with equal flow conditions the twodimensional nozzle velocity decay is initiated sooner (closer to the nozzle exit) than that of the conic nozzle. In the initial mixing region, the shape of the two curves cnce decay has bequn is the same although the absolute values differ, being a function of the nozzle aspect ratio. In the transition region the two-dimensional nozzle plume decay follows an $x^{-1 / 2}$ decay rate. Finally in the fully-mixed region, the slope of both curves follow an $x^{-1}$ decay rate. Although not shown in the figure, the plume centerline static temperature decay curves for the two configurations are similar to the velocity decay curves shown in Fig. 4; however, the static temperature decay curve is displaced to the left of the velocity decay curve, thereby indicating an earlier initiation of decay.

In Fig. 5, the effect of two-dimensional noz$z$ le aspect ratio on the plume centerline velocity decay is shown schematically. With increasing aspect ratio, the initiation of the velocity decay curves shifts to increasingly smaller axial distances from the nozzle exit plane. Similar trends are obtained for the variation of the plume static temperature curves with two-dimensional nozzle aspect ratio.

\section{Data Correlation Considerations}

Data on the effect of ejector flow on twodimensional engine exhaust plume centerline velocity and temperature decay are very limited. However, free-flight effects on some plume decay characteristics are available and can be used to estimate ejector flow or secondary stream effects on the engine plume decay, particularly near the nozzle exit plane where the confined flow due to the ejector walls is not too important. With both the free-stream and ejector flow, the engine exhaust plume core is lengthened and the plume spreading rate is reduced. Furthermore, conic nozzle plume decay data with a secondary stream also can be used to help estimate the secondary stream effects on two-dimensional nozzle plume decay by suitable analogy. Similarly, it will be shown that the effects of plume shear layer excitation on conic nozzle plume centerline decay characteristics can be extrapolated to two-dimensional nozzle plumes.

The key to the preceding analys is problems when insufficient data are available to establish the various plume centerline decay characteristics for asymmetric nozzles is the universal relationship of the local plume centerline static temperature to local plume centerline velocity for the entire axial length of single-stream plumes irrespective of nozzle shape. This relationship was established for conic nozzles in Ref. 4 and is applicable also to excited plumes and plumes in a secondary stream.

\section{Secondary Stream Effects on Plume Decay}

The effect of a secondary stream on jet plumes has been studied for many years, by numerous investigators, an example being Ref. 5 . For the most part these studies have been limited to conic nozzles. However, in Ref. 6, cold-flow plume centerline velocity decay in a moving airstream is reported for a two-dimensional nozzle with an aspect ratio of 12 . In Ref. 7, an analytical method is presented for predicting axisymmetric plume characteristics in a moving airstream. This reference also contains previously published data in this field, including that of Ref. 5 . The analysis of Ref. 7 is also shown to apply to the two-dimensional nozzle data of Ref. 6 in the nozzle height ( $Z$ ) plane. In order to correlate the two-dimensional nozzle data of Ref. 6 with conic nozzle plume decay data, the author of Ref. 7 
resorted to different constants in the analys is, a different constant was necessary for each nozzle type.

The effects of a secondary stream on all of the two-dimensional nozzle plume characteristics of interest are not available. Where such data are not directly available, the secondary stream effect on such nozzle plumes can be evaluated by analogy from corręlated static two-dimensional nozzle plume data ${ }^{3}$ and conic nozzle plume decay data for which both static and moving stream data are available. 1,2 Typical of such data useful to establish the necessary analogies are shown in Figs. 6 and 7 , taken from Ref. 3. In Fig. 6, the variation of the local plume centerline static temperature ratio is shown for two dimensional nozzles and orifices. Also shown is the correlation curve for conic nozzles taken from Ref. 1. In Fig. 7, the local plume centerline static temperature ratio variation with local plume centerline velocity ratio is shown for several secondary stream-to-jet velocity ratios for conic nozzles. 5,8 Similar data to that shown in Fig. 7 are not available for two-dimensional nozzles at this time.

\section{Plume Centerline Decay Correlations}

Velocity. The plume centerline velocity decay with a secondary stream (moving airstream) is shown in Fig. 8 for a two-dimensional nozzle with an aspect ratio of 24.6 The data shown are presented in conventional terms of $\left(U_{c}-U_{0}\right) /\left(U_{j}-U_{0}\right)$ as a function of axial distance from the nozzle exit plane. Also shown in the figure are data for a static flow condition $\left(U_{0}=0\right)$ taken from Ref. 9. With increasing seccndary stream-to-jet velocity ratio, $U_{0} / U_{j}$, the decay data shifts to increasingly greater axial distances from the nozzle exit plane. Similar trends are obtained with conic nozzles. 1,5

In order to correlate the preceding data on a single curve, a parameter $F_{0}$, was developed. The variation of $F_{0}$ with the velocity ratio, $U_{0} / U_{j}$, is shown in Fig. 9 for conic nozzles and a twodimensional nozzle with an aspect ratio of 24 . The solid curves through the data were calculated using the following equation:

$F_{0}=1+0.725(A R)^{0.33}\left(U_{0} / U_{j}\right)^{1.33} /\left(1-U_{0} / U_{j}\right)^{0.125}$

The secondary stream parameter, $F_{0}$, was selected to provide limit values of 1.0 when $U_{0} / U_{j}$ was 0 and infinity when $U_{0} / U_{j}$ was 1 ; consequently, Eq. (1) is not valid when $U_{0} / U_{j}$ is greater than 1 , as in some studies.

For $U_{0} / U_{j}$ values less than 0.8 , Eq. (1) can be simplified to:

$$
F_{0}^{\prime}=1+0.9(A R)^{0.33}\left(U_{0} / U_{j}\right)^{1.5}
$$

A comparison of $F_{0}$ with $F_{0}$ values for various $U_{0} / U_{j}$ ratios is shown in Table 1 . The table indicates that the differences between $F_{0}$ and $F_{0}^{\prime}$ are small up to a Mach number of 0.8 , thus permitting the use of the simplified parameter $F_{0}^{\prime}$.
The correlated secondary stream data for the two-dimensional nozzle with an aspect ratio of 24 using the $F_{0}$ parameter is shown in $F i g .10$ in terms of $\left(U_{c}-U_{0}\right) /\left(U_{j}-U_{0}\right)$ as a function of $\mathrm{X} / \mathrm{bF}_{0}$. In Fig. 11 , the correlated secondary stream data for a conic nozzle ${ }^{5}$ using the $F_{0}$ parameter is shown. It is apparent from the data correlation in these two figures that the $F_{0}$ parameter correlates the plume centerline velocity decay extremely well for both the conic and twodimensional nozzles.

On the basis of the preceding data correlation technique, it appears reasonable to apply the $F_{0}$ parameter to the various static flow two-dimensional nozzle plume centerline velocity decay data included in Ref. 3 in order to estimate the plume centerline velocity decay when a secondary stream is present.

Static temperature. Two-dimensional nozzle plume centerline static temperature decay in a secondary stream data were not available for this study. However, such data were available for a conic nozzle. 5 Correlation of these data was successfully accomplished also by the use of the $F_{0}$ parameter used to correlate the plume centerline velocity decay. The correlated data are shown in Fig. 12 in terms of $\left(t_{c}-t_{a}\right) /\left(t_{j}-t_{a}\right)$ as a function of $X / D_{j} F_{0}$. Again good correlation of the data was obtained, as was the case for the velocity decay data from the same reference and shown in the previous figure.

On the basis of the correlation of the conic nozzle plume centerline static temperature decay shown in Fig. 12 and by analogy to the preceding conic and two-dimensional nozzle plume centerline velocity decay correlation, it appears feasible to use the $F_{0}$ parameter to correlate or estimate the plume centerline static temperature decay for two-dimensional nozzles in a secondary stream. Thus the curve in Fig. 7 that was initially developed from conic nozzle plume data is considered to be applicable also for two-dimensional nozzle plumes with secondary streams.

\section{Plume Radial Decay}

The literature contains some data on the radial velocity decay of two-dimensional nozzle plumes with a secondary stream. No such data are available for the radial static temperature decay. Consequently, the effect of a secondary stream on two-dimensional nozzle plume radial static temperature decay must be estimated from an analogy approach. Furthermore, plume radial decay data with a secondary stream are available only in the nozzle height ( $Z$ ) plane. Thus, it must be assumed that the plume radial decay in the nozzle width (Y) plane follows similar tronds.

Velocity. The effect of a secondary stream on the plume radial velocity decay is shown in Fig. 13 for a nozzle aspect ratio of 24 . The data shown were taken from Ref. 6 and are in the nozzle height ( $Z$ ) plane. In Fig. 13(a), the plume radial velocity decay for several $U_{0} / U_{j}$ ratios are shown at a nominal $x / D_{e}$ of 2.7 . The plume radial velocity decay curve for a conic nozzle is also shown in the figure as a basis for comparison. It is apparent that the conic nozzle and twodimensional nozzle plumes have similar radial decay characteristics. In Fig. 13(b), the plume 
radial velocity decay for the two-dimensional nozzle data of Ref. 6 is shown in the nozzle height (Z) plane for several $X / D_{e}$ locations and at a constant $U_{0} / U_{j}$ ratio of 0.5 . For comparison, the conic nozzle plume radial velocity decay curve is again shown. At all $\times / D_{e}$ locations, the plume radial velocity decay data for the two-dimensional nozzle is again seen to coincide with the conic nozzle plume curve.

Static temperature. In Ref. 3, the plume radial static temperature and velocity decay for ambient external conditions were represented by similar relationships. With a secondary stream, the plume radial velocity decay was shown to be a function of the secondary stream velocity in the preceding section and Fig. 13. However, the plume radial static temperature decay is assumed herein to remain a function of the ambient static temperature rather than that of the secondary stream. The assumed variation of the plume radial static temperature decay with a secondary stream is shown in Fig. 14 in terms of $\left[\left(t_{R}-t_{a}\right) /\left(t_{c}-t_{a}\right)\right]_{z}$ as a function of $z / Z_{0.5}$. This curve is identica? to plume radial static temperature decay curve given in Ref. 3 for ambient external conditions.

\section{Plume Decay Modification}

Plume velocity/temperature decay and spreading characteristics can be modified by exciting or perturbing the coherent large-scale structure in the plume shear layer. Excitation of the plume shear layer can be achieved py acpustic, aerol mechanical or thermal means. $10-13$ Also results obtained by excitation of the plume shear layer are independent of the nozzle shape, excitation having been successfully applied to plumes of conic (circular) nozzles, dual flow nozzles 14,15 and two-dimensional nozzles. 16-20

Amplification or excitation of large-scale structures in jet plumes can occur when the perturbation frequency is the same as the natural frequency of the coherent large-scale structure in the shear layer. 1 The magnitude of the largescale structure amplification is a function of the perturbation strength (acoustic level for acoustic excitation), jet flow conditions and location of the perturbation source relative to the plume (within the nozzle or external to the nozzle). By-products of plume excitation can include increased turbulence levels in the plume resulting in some increase in jet noise level. 1 It is further stated in Ref. 19 that two-dimensional plumes are more sensitive to external excitation than Ref. 17 and others suggest. Indeed, data in Ref. 19 indicates an extreme frequency sensitivity in the excitation of a plume that is also borne out in unpublished conic nozzle work by the Lockheed-Georgia Corporation under contract to NASA. Very small changes in excitation Strouhal number can produce large changes in the largescale and turbulence structures of the plume shear layer. This may help to explain some of the anomalous behavior present in the current available experimental data.

Most of the available experimental plume excitation data have been obtained with an acoustic excitation source, cold flow and small-scale models over a range of subsonic and low supersonic jet Mach numbers. In general, the data have been obtained only along the plume centerline in the nozzle height $(Z)$ plane. Oniy limited data are available on the effect of plume spreading under the influence of an excitation source. Finally, while some data are available, the effect of temperature level on the plume velocity decay of an excited plume is presently not understood. A heated jet plume shows a response to excitation that depends on jet Mach number and temperature. This response decreases with both when the flow is turbulent.

The following sections present a brief overview of some of the available information on the effect of excitation on plume decay characteristics. For the most part the excitation source is acoustic, although similar effects have been reported in the literature using other sources.

\section{Excited Plume Centerline Decay}

In cold-flow studies directed toward more rapid plume decay, excitation has achieved more rapid decay of the centerline velocity compared with that of unexcited plumes. These results were obtained with both laminar and turbulent flows and are documented in the literature. Limited unpublished data with a heated, internally acoustically excited conic jct have also been obtained by the Lockheed-Georgia Corporation under contract to NASA, as previously cited, in a continuation of the work reported in Ref. 1 . In the laminar flow regime $\left(M_{j}, 0.3\right)$, acoustic excita$t i o n$ produced a much more rapid plume centerline velocity decay than that obtained without excitation. However, in the turbulent flow regime $\left(M_{j}\right.$, 0.8 and 1.15 ), the effect at a given acoustic level decreased with increasing jet temperature ratio, $\mathrm{T}_{\mathrm{j}} / \mathrm{T}_{\mathrm{a}}$. For example, with a conic nozzle, a jet Mach number of 0.8 and an acoustics excitation level of $150 \mathrm{~dB}$, only small effects on the plume centerline velocity decay were obtained at a $T_{j} / T_{a}$ of 2.3 , whereas significant decay effects were obtained with cold flow and otherwise similar conditions. Possible reasons for this phenomenon are discussed in Ref. 21. In this reference it is stated that plume excitation by external sources, including acoustic means, is tied to the jet flow state. Cold flow jets that are convectively unstable jets, according to Ref. 21, apparently can be excited. However, hot jets that are absolutely unstable flows maintain fluctuations independent of external acoustic excitation. This phenomenon needs further study to verify the important consequences of these findings. It is also necessary to determine whether other means of excitation than acoustics could have similar restrictions to their effectiveness.

In Ref. 4, limited unpublished static plume centerline decay data for a conic nozzle with and without excitation were included. These data obtained by the Lockheed-Georgia Corporation under contract to NASA are reproduced in $\mathrm{Fig} .15$ as the variation of $\left(t_{c}-t_{a}\right) /\left(t_{j}-t_{a}\right)$ with $U_{c} / U_{j}$, the data were taken with a $5.08 \mathrm{~cm}$ diameter noz$z l e$, a jet Mach number of 0.8 and a jet total temperature of $489 \mathrm{~K}$. An acoustic excitation level of $147 \mathrm{~dB}$ with a Strouhal excitation number of 0.35 resulted in the data shown. The data obtained with a rotating disk turbulator were also taken from Ref. 4 but were originally published in Ref. 12. Also shown in the figure is the unexcited jet decay curve for conic nozzle taken from Ref. 4. The data shown indicate that 
both the excited and unexcited data are represented by the same curve. Furthermore in Fig. 6 it was shown that the unexcited static plume centerline velocity/temperature decay data for two-dimensional nozzles also fell on conic nozzle curve. On the basis of these considerations, it $c$ an be assumed that, by analogy, excited plume centerline decay data are also represented by the curve shown in Fig. 15.

\section{Excited Plume Radial Decay}

Excited two-dimensional nozzle plume radial decay data are presently not available in the open literature. However, such data (unpublished) have been obtained for conic nozzle plumes by the Lockheed-Georgia Corporation under contract to NASA and are shown and discussed in the following sections.

Velocity. Representative excited and unexcited conic nozzle plume radial velocity decay data (unpublished) are shown in Fig. 16. Also shown for comparison is the correlation curve from Ref. 4. It is evident that both excited and unexited plume radial velocity decay are represented by this curve and hence have the same decay rates.

In Ref. 2 it was shown that unexcited conic and two-dimensional nozzle plumes have the same radial velocity decay rates when analyzed using nondimensional parameters. Because the excited and unexcited conic nozzle plume radial velocity a iso have the same radial velocity decay rates, it can be assumed with a high degree of confidence that, by analogy, excited two-dimensional nozzle plume radial velocity decay is also represented by the curve shown in Fig. 16.

Static temperature. Typical excited and unexcited conic nozzle plume radial static temperature decay data (unpublished) are shown in Fig. 17. Also shown is the correlation curve from Ref. 4. As in the case of the plume radial velocity decay, both excited and unexcited plume radial static temperature decay are represented by the same curve and consequently have similar decay rates. on the rationale as just discussed for the plume radial velocity decay, it can be assumed that, by analogy, excited and unexcited two-dimensional nozzle plume radial static temperature decay are also represented by the curve in $\mathrm{Fig} .17$.

\section{Excited Plume Spreading}

Although the literature contains some data on excited plume spreading characteristics for twodimensional nozzle plumes (e.g., Ref. 18), the data are insufficient to provide the base for the necessary correlation parameters. However, the studies indicate that excitation enhances both the plume velocity and static temperature spreading rates as a function of the perturbation strength. In Ref. 19, an increase of up to 45 percent was obtained in the spreading rate in the nozzle height (Z) plane with acoustic levels of $105 \mathrm{~dB}$. It should be noted that the preceding results were obtained with an aspect ratio of 48 and the jet confined between side plates in the nozzle width (Y) plane. Strouhal numbers from 0.083 to 1.745 were included in the study, with the maximum plume spreading occurring with a Strouhal excitation number of 0.29. However, as in the case of the excited plume centerline decay, a satisfactory general correlation for excited heated jet spreading is not currently available.

\section{Secondary Stream Effects Or. Excited Plume Decay}

The effect of a secondary stream on an excited two-dimensional nozzle plume causes the same order of magnitude change in the plume decay as that for an unexcited plume. Thus, the curve in Fig. 7 can be used to estimate the excited plume centerline temperature decay in the presence of a secondary stream (ejector or flight) by substituting $\left(U_{c}-U_{0}\right) /\left(U_{j}-U_{0}\right)_{\text {exc }}$ and $\left(t_{c}-t_{0}\right) /\left(t_{j}-t_{0}\right)_{\text {exc }}$
for the respective unexcited ratios shown in the figure.

The effect of a secondary flow on the centerline decay of an excited two-dimensional nozzle plume must be determine by analogy to excited conic nozzle plume centerline decay data. In Fig. 18, the excited conic plume velocity ratio, $\left(U_{c}-U_{0}\right) /\left(U_{j}-U_{0}\right)_{\text {exc }}$ is plotted as a function of the unexcited nozzle centerline plume velocity velocity ratio $\left(U_{c}-U_{0}\right) /\left(U_{j}-U_{0}\right)$ unexc for several axial stations. In the figure, the static data $\left(U_{0} / U_{j}=0\right)$ are shown by the circle symbols while the data with a secondary stream $\left(U_{0} / U_{j}=0.43\right)$ are shown by the square symbols. Both sets of data fall on the same curve (solid line in the figure). It is apparent from these data that, over the range of data shown, the same relationship exists between excited and unexcited plumes with and without a secondary stream. Furthermore, on this basis it appears reasonable, by analogy, that the curve shown in Fig. 18 also is applicable to excited plumes with secondary streams if the excited static temperature and excited velocity ratios are substituted for the corresponding static ratios.

\section{Concluding Remarks}

From the preceding discussions of excited jet plume characteristics, it is evident that when the plume large-scale shear layer structure is modified by excitation, large changes in the rate of plume centerline velocity and static temperature decay as well as in the plume spreading rate $c$ an be achieved with and without a secondary stream. Such changes in the plume characteristics can beneficially influence the design, weight and performance of an ejector for both conic and asymmetric nozzle systems. While the excited data were obtained by acoustically exciting the plume, the literature, as previously stated, indicates other means can be used, such as aero/mechanical or thermal means. These latter means may perhaps avoid the tomperature problems that have been encountered to date with acoustic excitation.

\section{Conclusions}

On the basis of a study concerned with secondary stream and plume excitation effects on twodimensional nozzle plume decay and spreading characteristics, the following conclusions are made:

1. Secondary stream effects on two-dimensional nozzle plume centerline velocity and static temperature decay characteristics were correlated to similar data for ambient conditions by the inclusion of appropriate flow and configuration parameters. 
2. Artificial excitation of the coherent large-scale structure in the plume shear layer produced more rapid plume decay and spreading of two-dimensional plumes in a manner similar to that previously observed with conic nozzle plumes.

3. Correlations developed in the present study provide a means of estimating the plume centerline velocity and static temperature decay for twodimensional nozzles from cold-flow plume centerline decay measurements for both secondary stream and artificial excitation effects.

4. Two-dimensional nozzle plume radial velocity decay with excitation and/or a secondary stream showed similar rates of decay as those for ambient external flow conditions.

\section{References}

1. Ahuja, K.K., Lepicovsky, J., Tam, C.K.W., Morris, P.J., and Burrin, R.H., "Tone Excited Jet: Theory and Experiments, "NASA CR-3538, 1982 .

2. von Glahn, U., "Correlation of Flight Effects on Centerline Velocity Decay for Cold-Flow Acoustically Excited Jets," NASA TM-83502, 1983.

3. von Glahn, U., "Two-Dimensional Nozzle Plume Characteristics," NASA TM-89812, 1987.

4. von Glahn, U., "On Some Flow Characteristics of Conventional and Excited Jets, "AIAA Paper 84-0532, Jan. 1984.

5. Pabst, 0., "Die Ausbreitung Heisser Gas strahlen in Bewegter Luft, "Deut. Luftfahrtforschung Um 8004, 8007, 1944. (Secondary Reference from AIAA Paper 85-0251, Jan. 1985)

6. Weinstein, A.S., Osterle, J.F, and Forstall, W., "Momentum Diffusion From a Slot Jet Into a Moving Secondary," Journal of Applied Mechanics, Vol. 23, No. 3, Sept. 1956, pp. 437-443.

7. Chu, C-W., "A Simple Analytical Method for Predicting Axisymmetric Turbulent Jet Flow$f$ ields in a Free-stream, " AIAA Paper 85-0251, Jan. 1985.

8. Tomich, J.F., and Weger, E., "Some New Results on Momentum and Heat Transfer in Compressible Turbulent Free Jets," AIChE Journal, Vol. 13, No. 5, Sept. 1967, pp. 948-954.

9. Forthmann, E., "Turbulent Jet Expansion," NACA TM-789, 1936.
10. Simmons, J.M., Lai, J.C.S., and Platzer, M.F., "Jet Excitation by an Oscillating Vane: AIAA Journal, Vol. 19, No. 6, June 1981, pp. 673-676.

11. Schwarz, I., "Jet Noise Suppression by Swirling the Jet Flow," AIAA Paper 73-1003, Oct. 1973.

12. Vulis, L.A., "Turbulent Mixing of Free Gas Jets, "Fluid Mechanics-Soviet Research, Vo1. 1, No. 3, May-June 1972, pp. 130-135.

13. Hasan, M.A.Z., and Hussain, A.K.M.F., "The Self-Excited Axisymmetric Jet, "Journal of Fluid Mechanics, Vol. 115, Feb. 1982, pp. 59-89.

14. Lu, H.Y., "Effect of Excitation on Coaxial Jet Noise as Observed by an Elliptic Mirror," AIAA Paper 81-2044, Oct. 1981.

15. von Glahn, U., "Preliminary Analysis of ToneExcited, Two-Stream Jet Velocity Decay," NASA TM-86951, 1985.

16. Sato, H., "The Stability and Transition of a Two-Dimensional Jet," Journal of Fluid Mechanics, Vol. 7, Part 1, Jan. 1960, pp. 53-80.

17. Chambers, F.W., and Goldschmidt, V.W. "Acoustic Interaction With a Turbulent Plane Jet - Effects on Mean Flow," AIAA Paper 81-0057, Jan. 1981.

18. Goldschmidt, V.W., and Kaiser, K.F., "Interaction of an Acoustic Field and a Turbulent Plane Jet: Mean Flow Measurements," AIChE Chemical Engineering Progress Symposium Series, Vol. 67, No. 109, 1971, pp. 91-98.

19. Thomas, F.0., and Goldschmidt, V.W., "Interaction of an Acoustic Disturbance and a TwoDimensional Turbulent Jet: Experimental Data," Journal of Fluids Engineering, Vol. 105, No. 2, June 1983, pp. 134-139.

20 Rockwe11, 0.0., "External Excitation of Planar Jet," Journal of Applied Mechanics, Vol. 39, No.4, Dec. 1972, pp. 883-890.

21. Bechert, D.W., "Excitation of Instability Waves," Zeitschrift fur Flugwissenschaften und Weltraumforschung, Vol. 9, No. 6, Nov.-Dec. 1985, pp. 356-361. 
TABLE 1.- TWO-DIMENSIONAL

NOZZLE SECONDARY STREAM

CORRELATION PARAMETERS

$(A R=1)$

\begin{tabular}{|c|c|c|}
\hline$U_{0} / U_{j}$ & $F_{0}$ & $F_{0}^{\prime}$ \\
\hline 0.1 & 1.034 & 1.029 \\
.2 & 1.087 & 1.081 \\
.33 & 1.174 & 1.171 \\
.5 & 1.314 & 1.318 \\
.67 & 1.488 & 1.494 \\
.8 & 1.659 & 1.544 \\
.9 & 1.840 & 1.769 \\
1.0 & $\infty$ & 1.900 \\
\hline
\end{tabular}



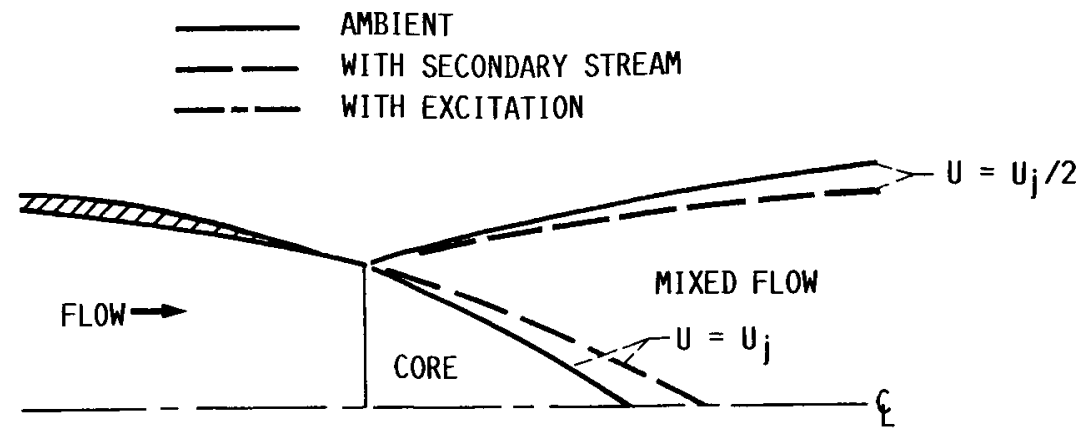

(A) SECONDARY STREAM.

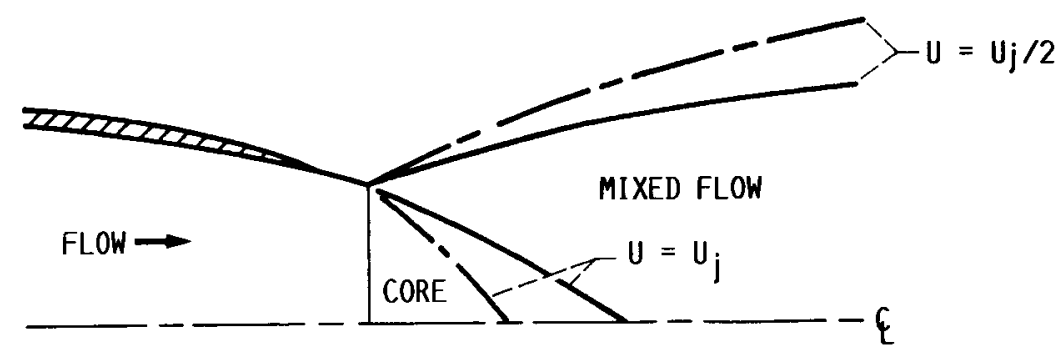

(B) SHEAR LAYER EXCITATION.

FIGURE 1. - SCHEMATIC SKETCH OF SECONDARY STREAM AND SHEAR LAYER EXCITATION EFFECTS ON JET PLUME VELOCITY DECAY.

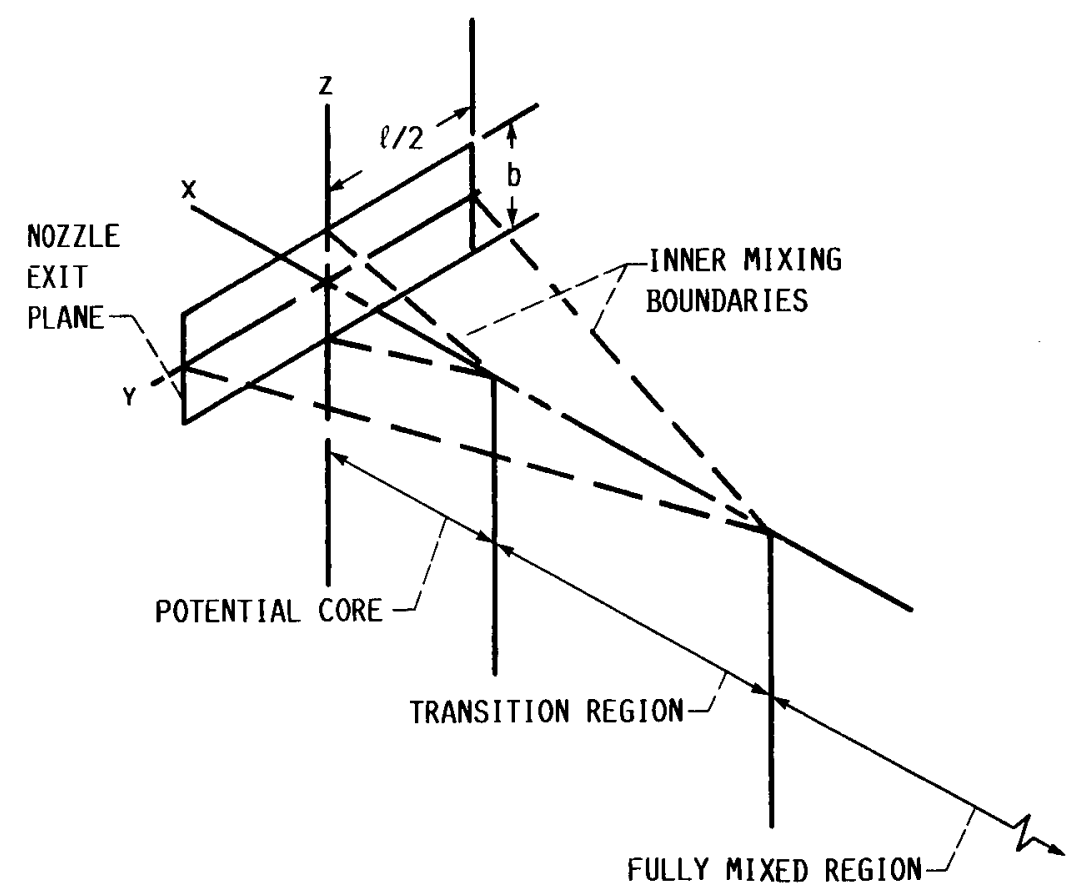

FIGURE 2. - SCHEMATIC SKETCH OF TWO-DIMENSIONAL NOZZLE PLUME SHOWING PERTINENT FLOW REGIONS. 

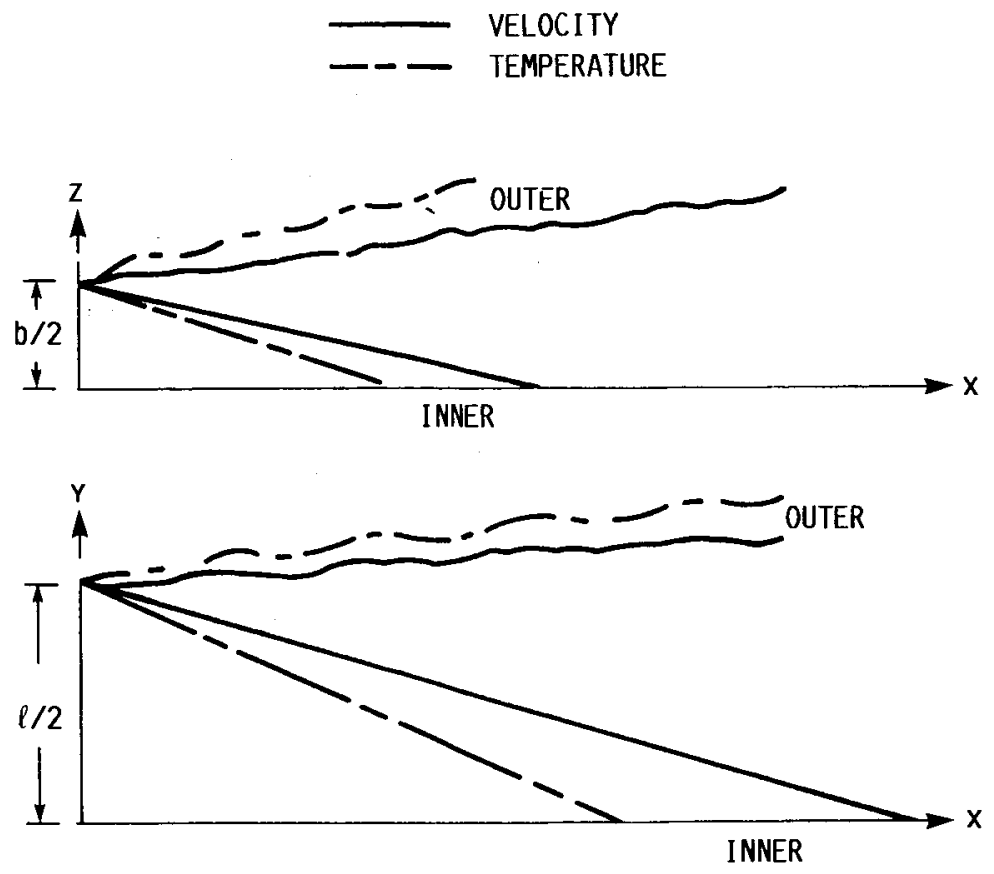

FIGURE 3. - SCHEMATIC SKETCH OF INNER AND OUTER $\left(U=U_{j} / 2\right)$ PLUME MIXING REGIONS.

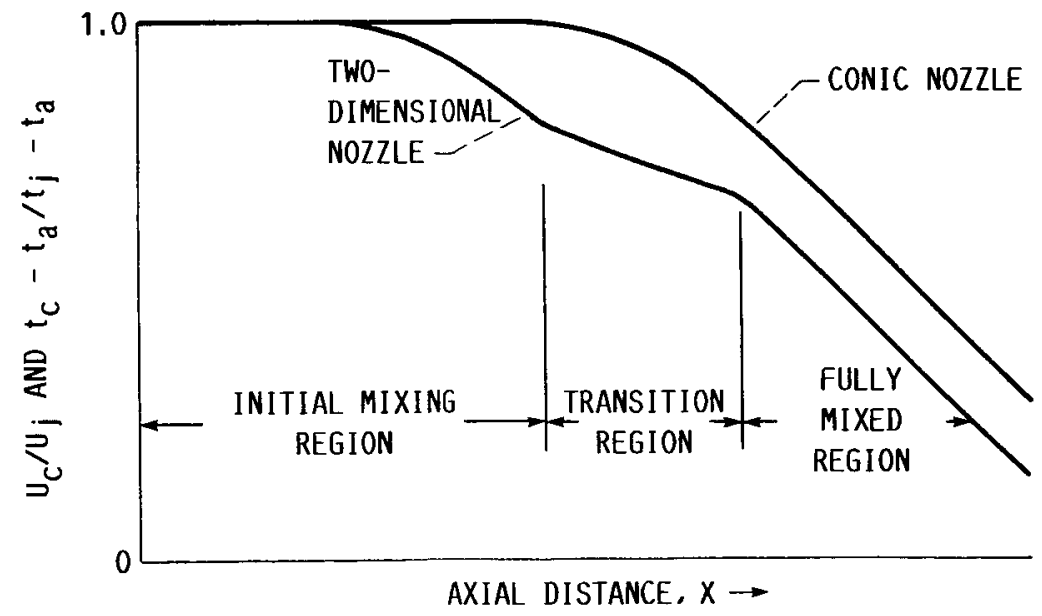

FIGURE 4. - SCHEMATIC SKETCH OF TWO-DIMENSIONAL NOZZLE CENTERLINE AXIAL VELOCITY AND TEMPERATURE DECAY. 


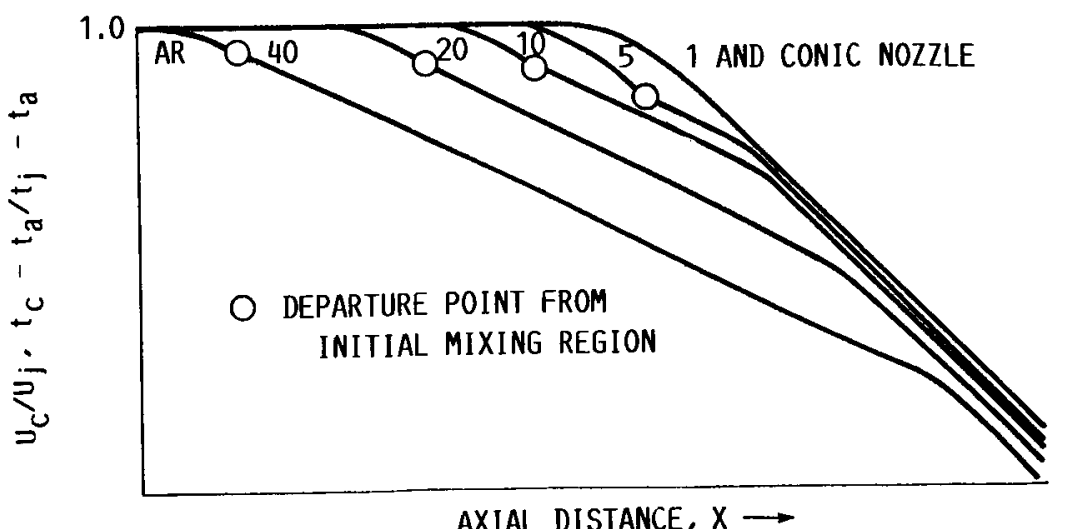

FIGURE 5. - SCHEMATIC SKETCH OF THE EFFECT OF TWODIMENSIONAL NOZZLE ASPECT RATIO ON THE PLUME CENTERLINE VELOCITY AND TEMPERATURE DECAY.

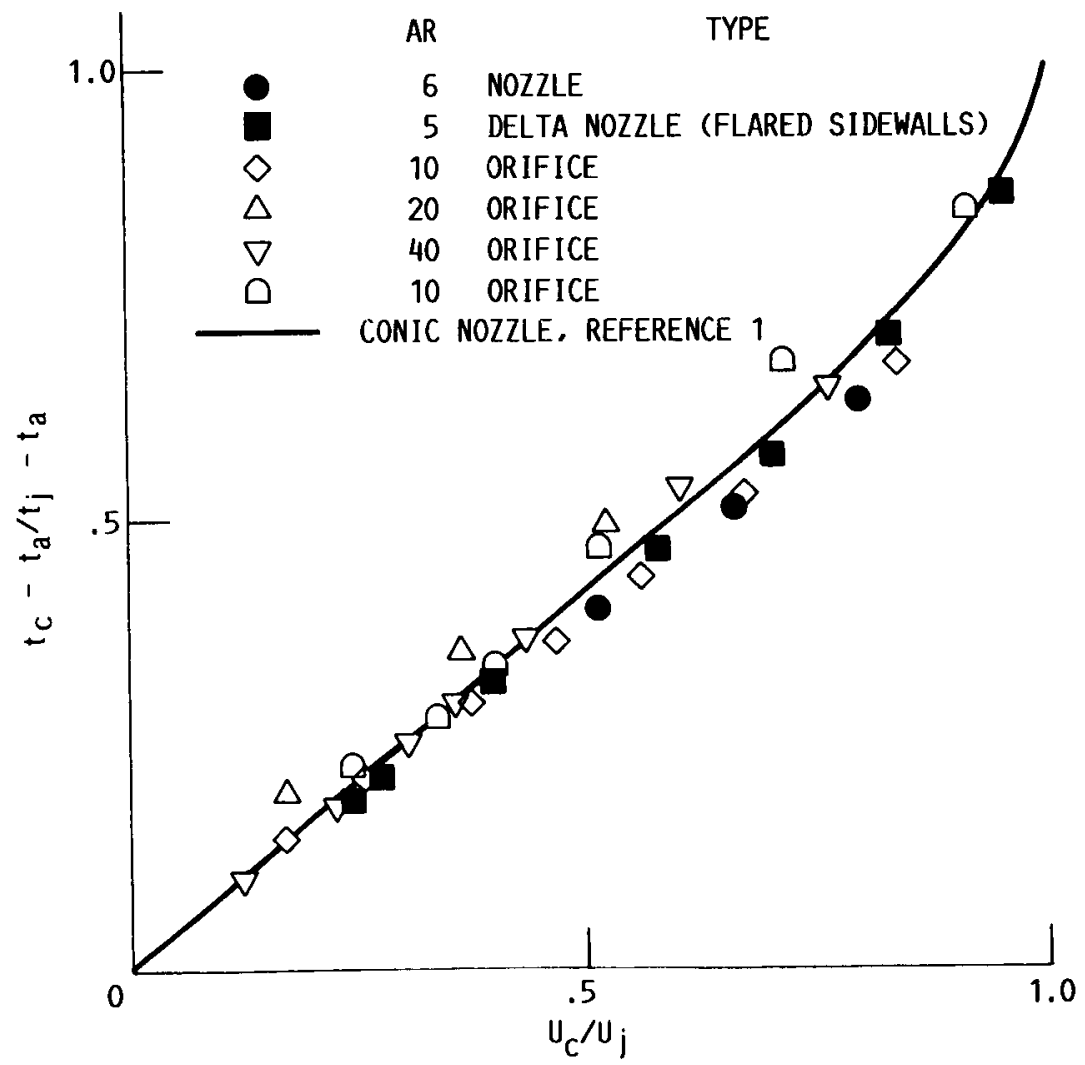

FIGURE 6. - TYPICAL VARIATION OF LOCAL PLUME CENTERLINE STATIC TEMPERATURE RATIO WITH LOCAL VELOCITY RATIO FOR TWO-DIMENSIONAL NOZZLES AND ORIFICES. REFERENCE 3. 


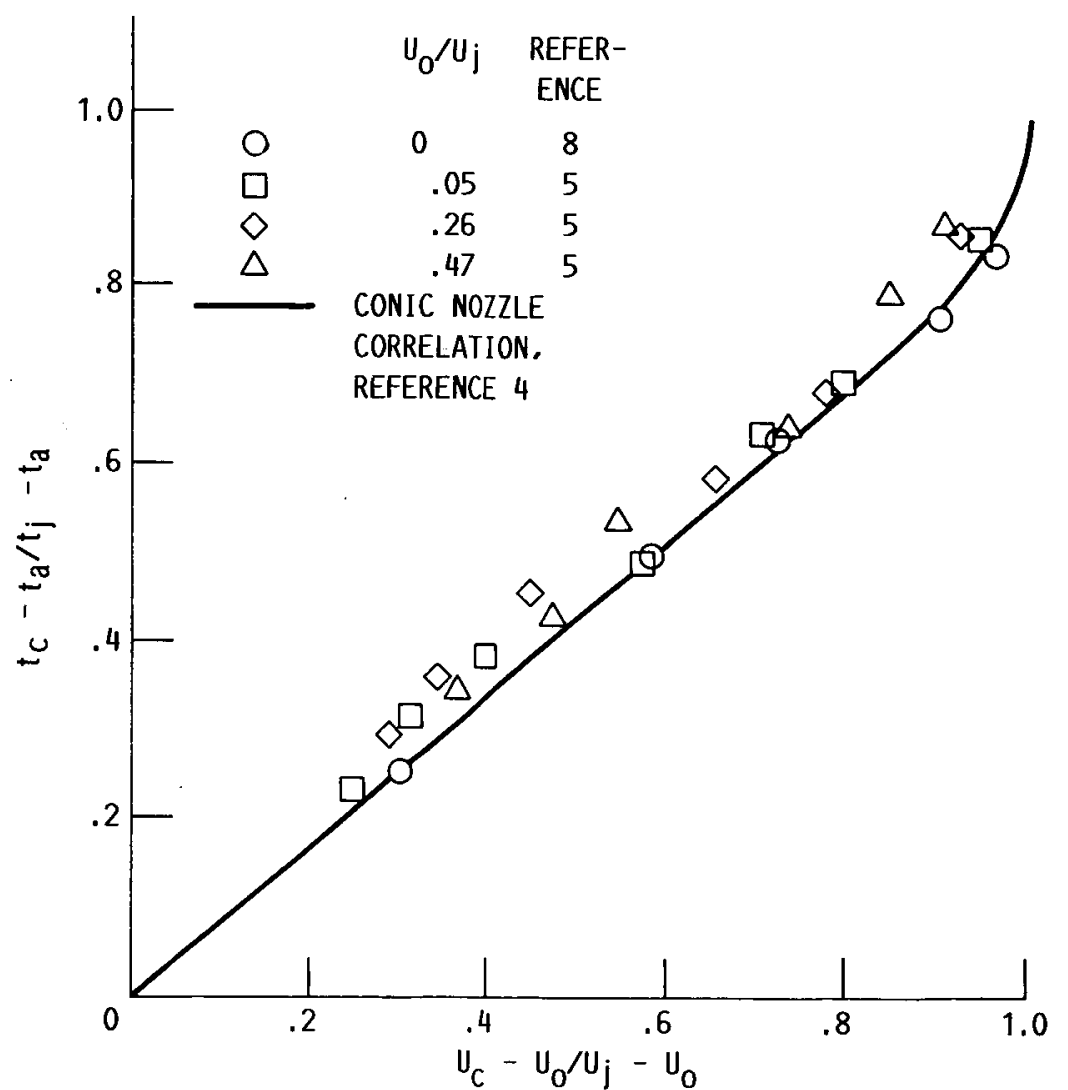

FIGURE 7. - CORRELATION OF PLUME CENTERLINE STATIC TEMPERATURE DECAY WITH VELOCITY DECAY FOR SEVERAL SECONDARY STREAM VELOCITY RATIOS. CONIC NOZZLES.

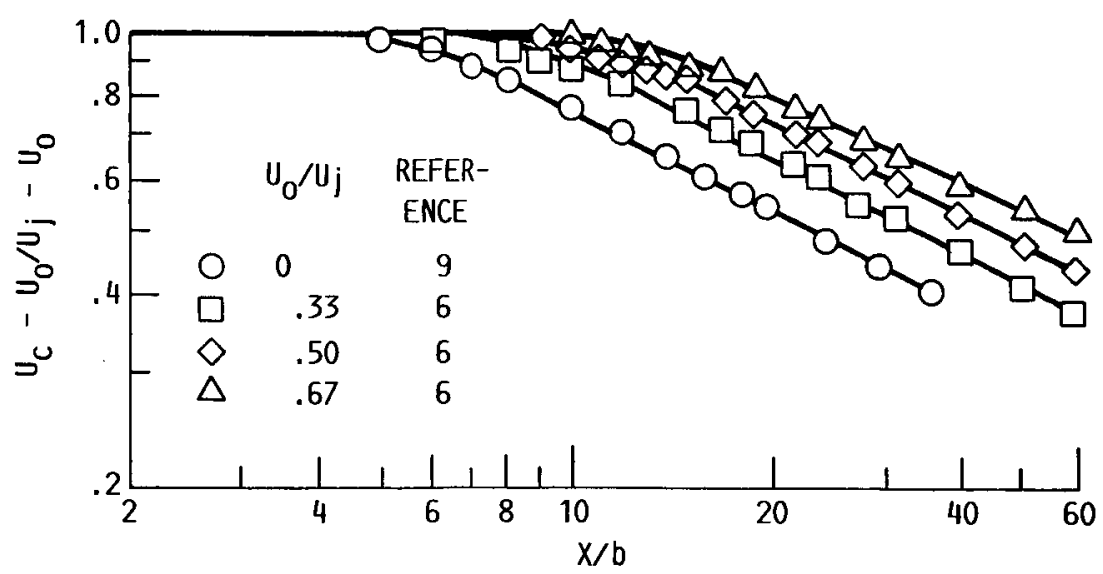

FIGURE 8. - EFFECT OF SECONDARY STREAM ON TWO-DIMENSIONAL NOZZLE PLUME CENTERLINE VELOCITY DECAY. AR, 24. 


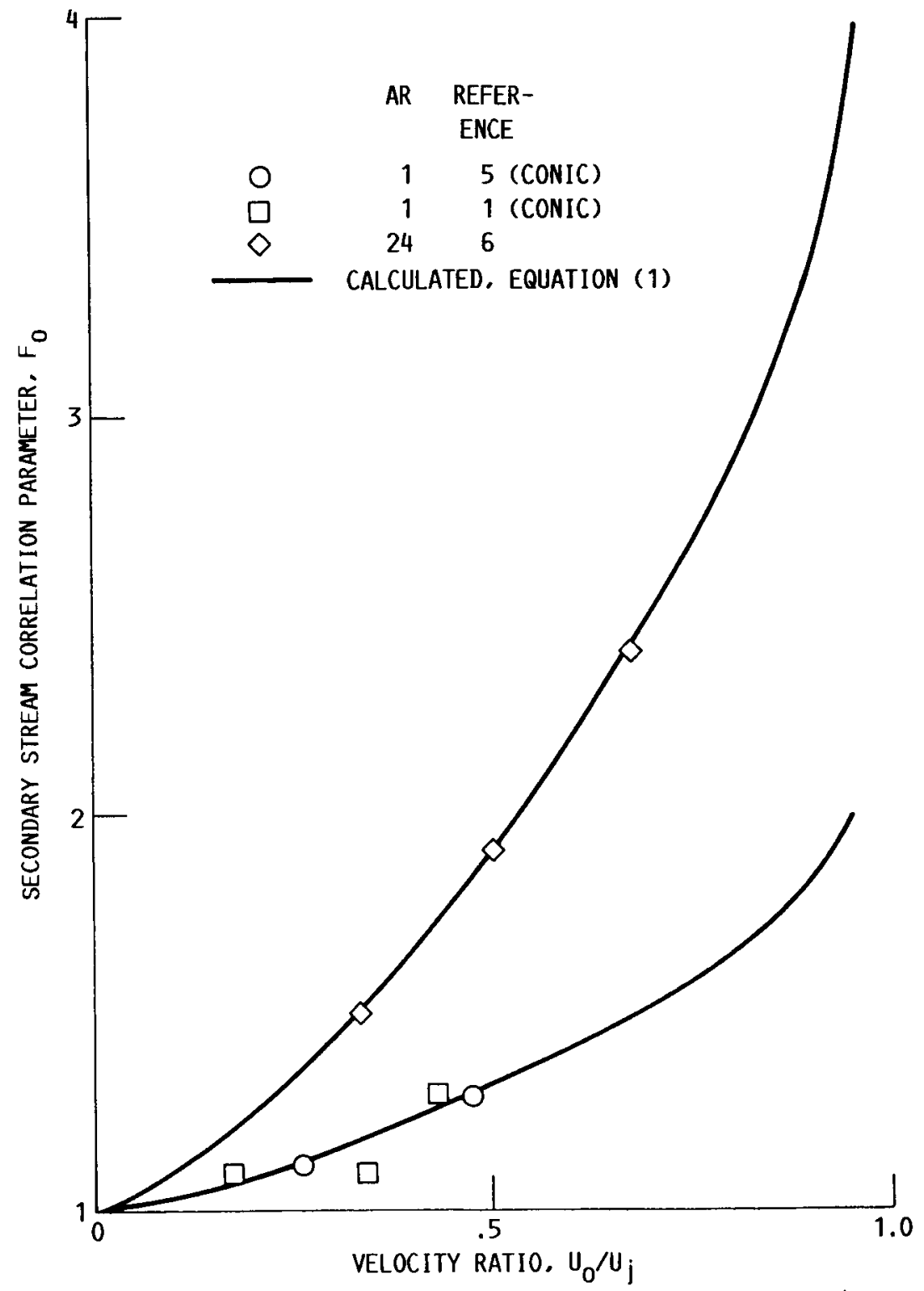

FIGURE 9. - VARIATION OF SECONDARY STREAM CORRELATION PARAMETER, $F_{0}$, WITH VELOCITY RATI0, $\mathrm{U}_{0} / \mathrm{U}_{j}$. 


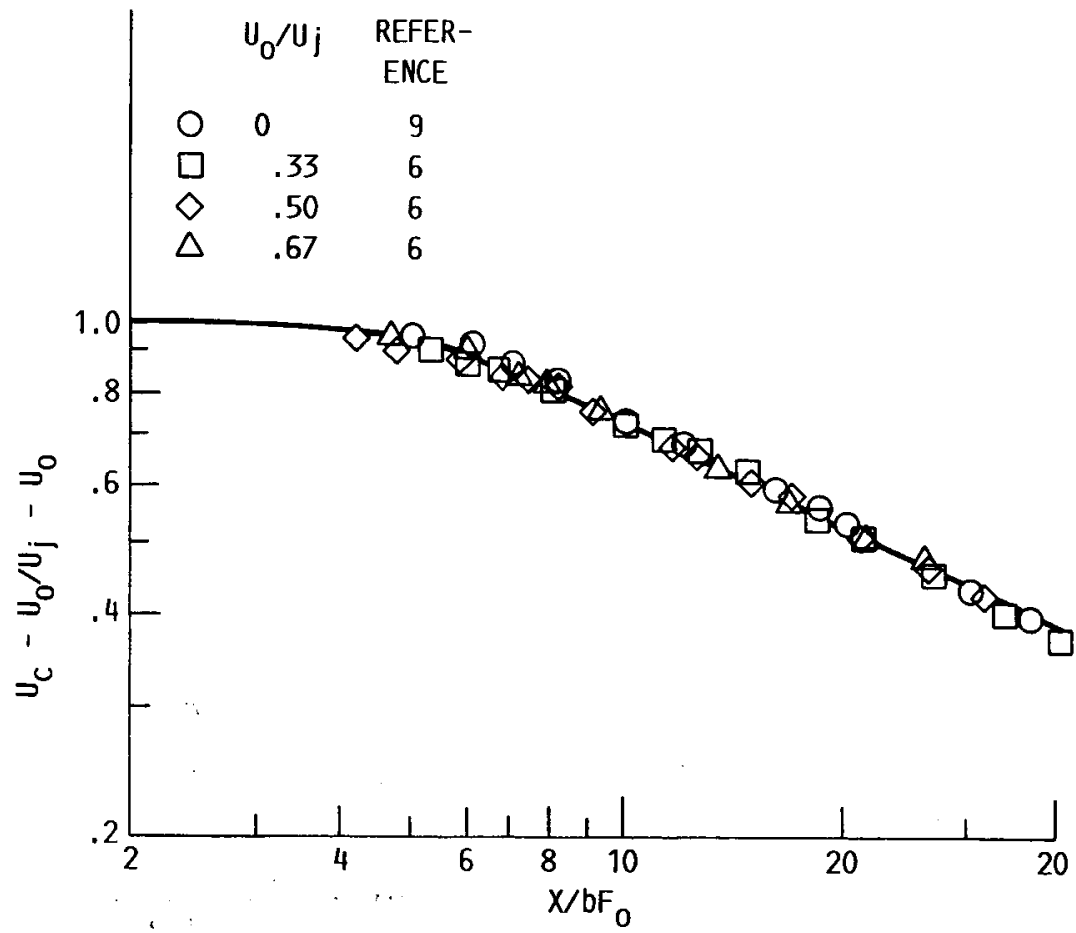

FIGURE 10. - CORRELATION OF SECONDARY STREAM EFFECT ON TWODIMENSIONAL NOZZLE PLUME CENTERLINE VELOCITY DECAY.

AR, 24.

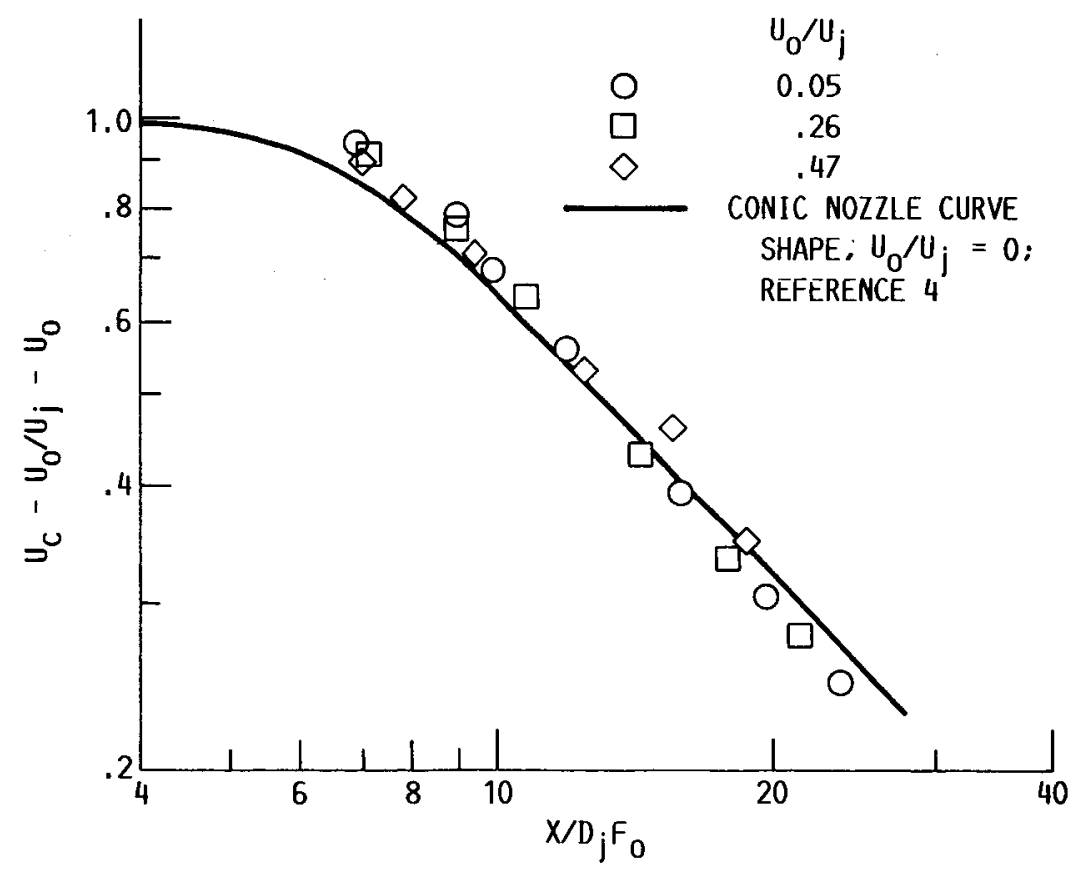

FIGURE 11. - CORRELATION OF SECONDARY STREAM EFFECT ON CONIC NOZZLE PLUME CENTERLINE VELOCITY DECAY. REFERENCE 5 DATA. 


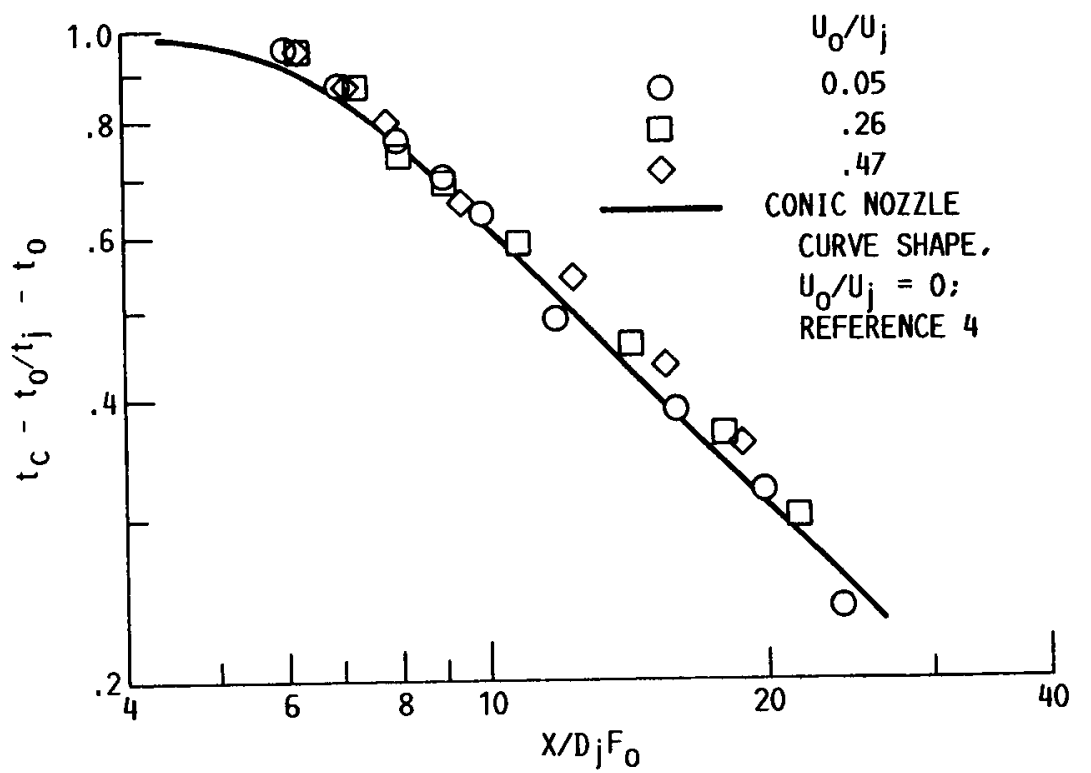

FIGURE 12. - CORRELATION OF SECONDARY STREAM EFFECT ON CONIC NOZZLE PLUME CENTERLINE STATIC TEMPERATURE DECAY. REFERENCE 5 DATA. 


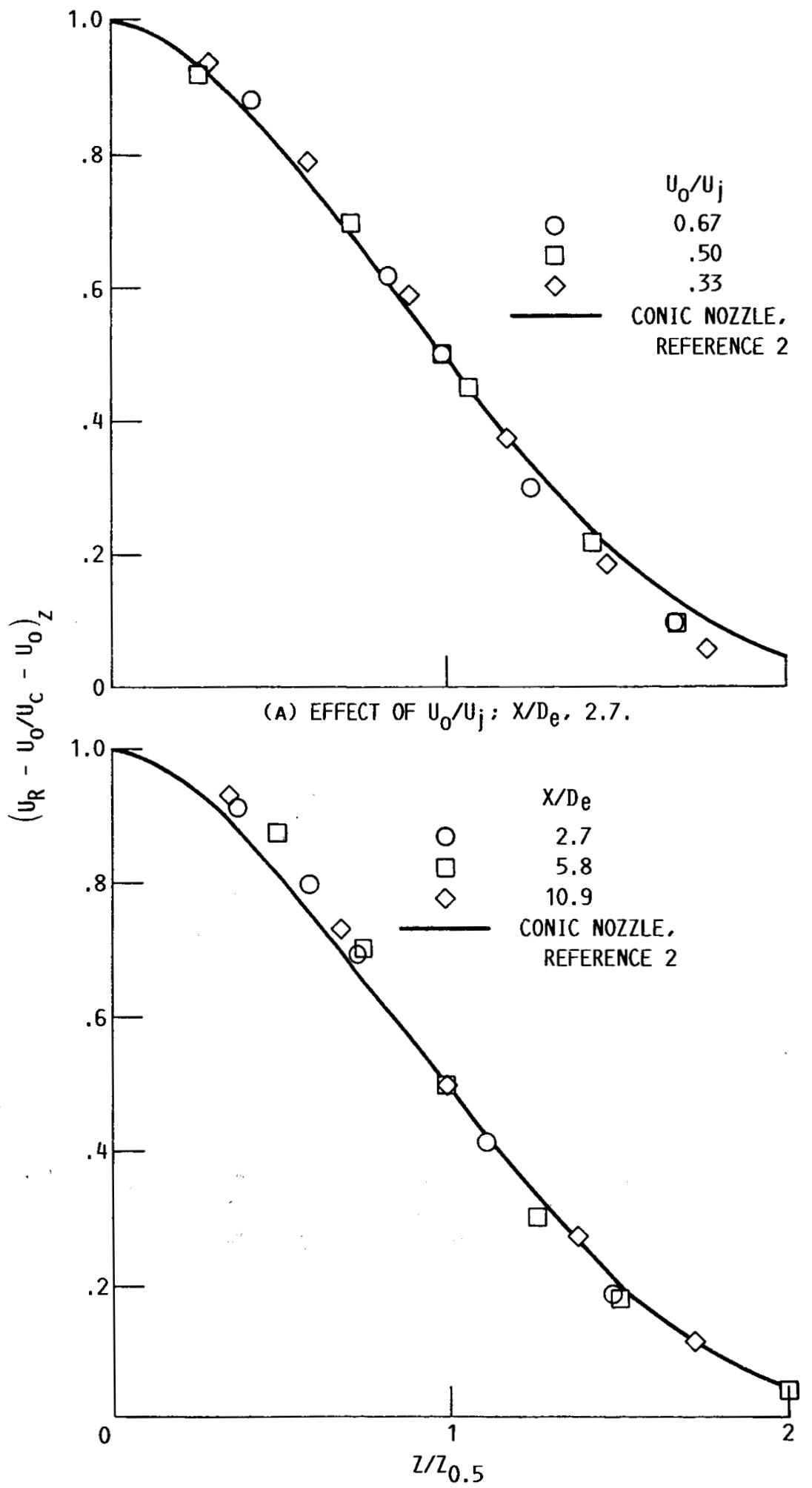

(B) EFFECT OF $X / D_{\mathrm{e}}: U_{0} / \mathrm{U}_{\mathrm{j}}, \mathbf{0 . 5}$.

FIGURE 13. - REPRESENTATIVE TWO-DIMENSIONAL NOZZLE PLUME RADIAL VELOCITY DECAY IN NOZZLE HEIGHT ( $Z$ ) PLANE WITH A SECONDARY STREAM. AR, 24: REFERENCE 6 DATA. 


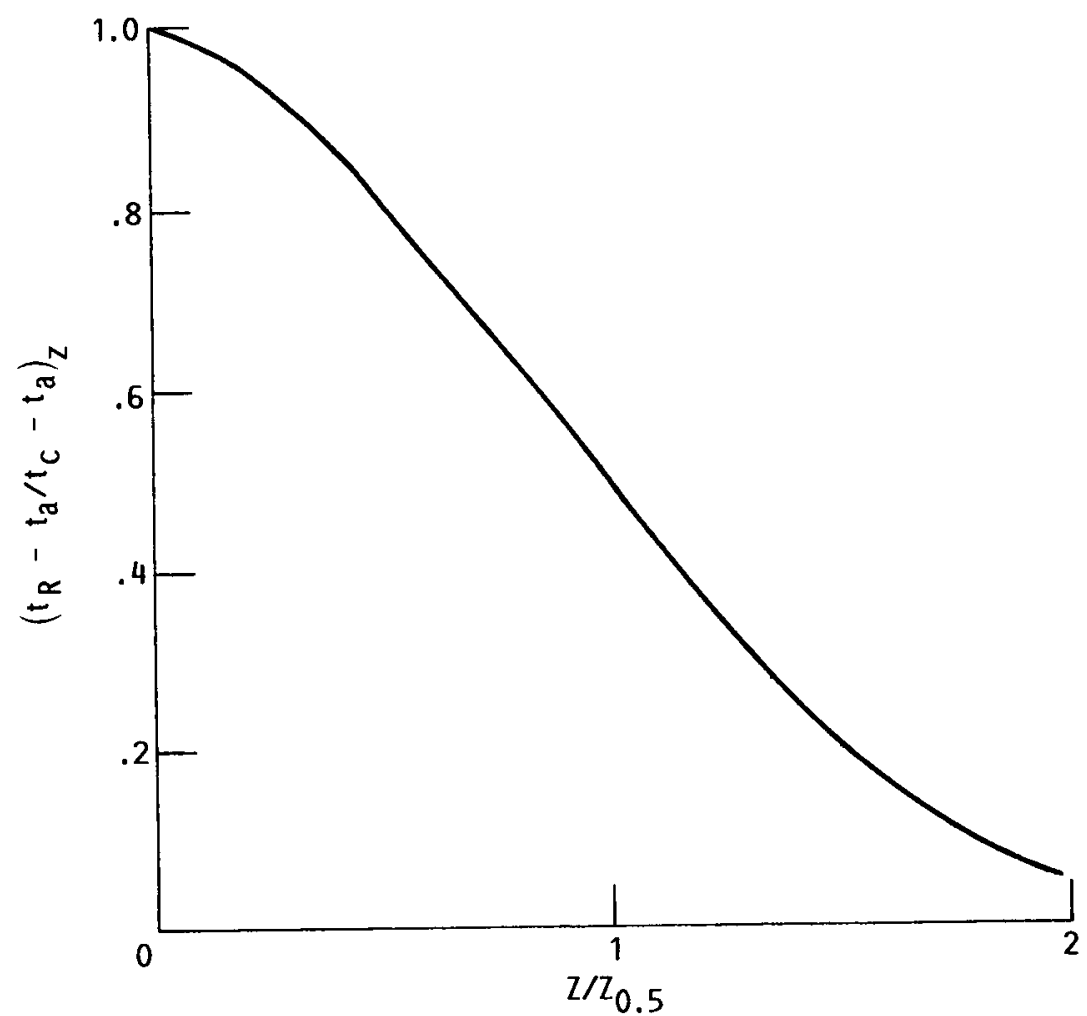

FIgURE 14. - REPRESENTATIVE TWO-DIMENSIONAL NOZZLE PLUME RADIAL STATIC TEMPERATURE DECAY IN NOZZLE HEIGHT (Z) PLANE WITH AND WITHOUT SECONDARY STREAM. 


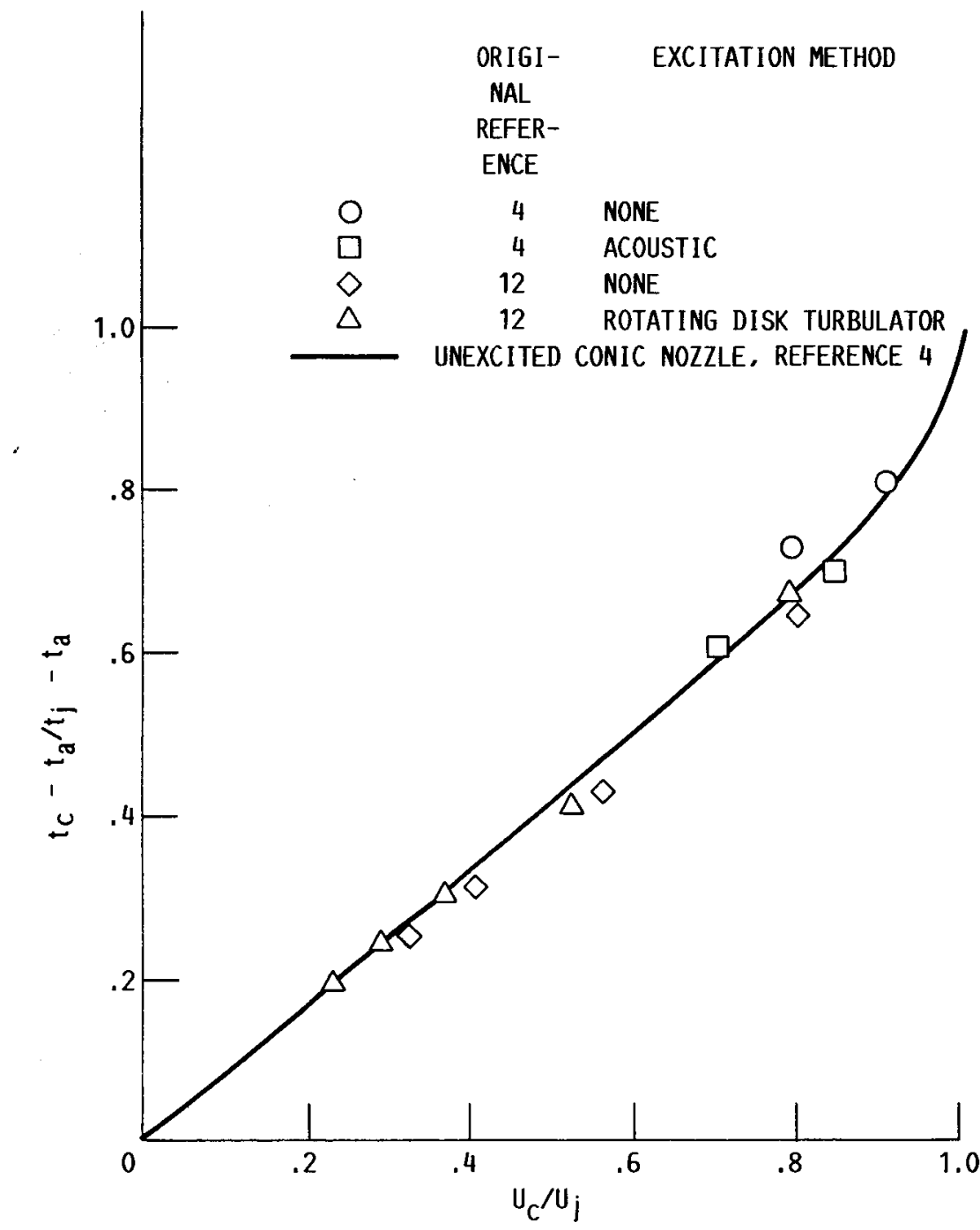

FIGURE 15. - PLUME CENTERLINE STATIC TEMPERATURE-TOVELOCITY VARIATION WITH AND WITHOUT FLOW EXCITATION. CONIC NOZZLE; REFERENCE 4 DATA. 


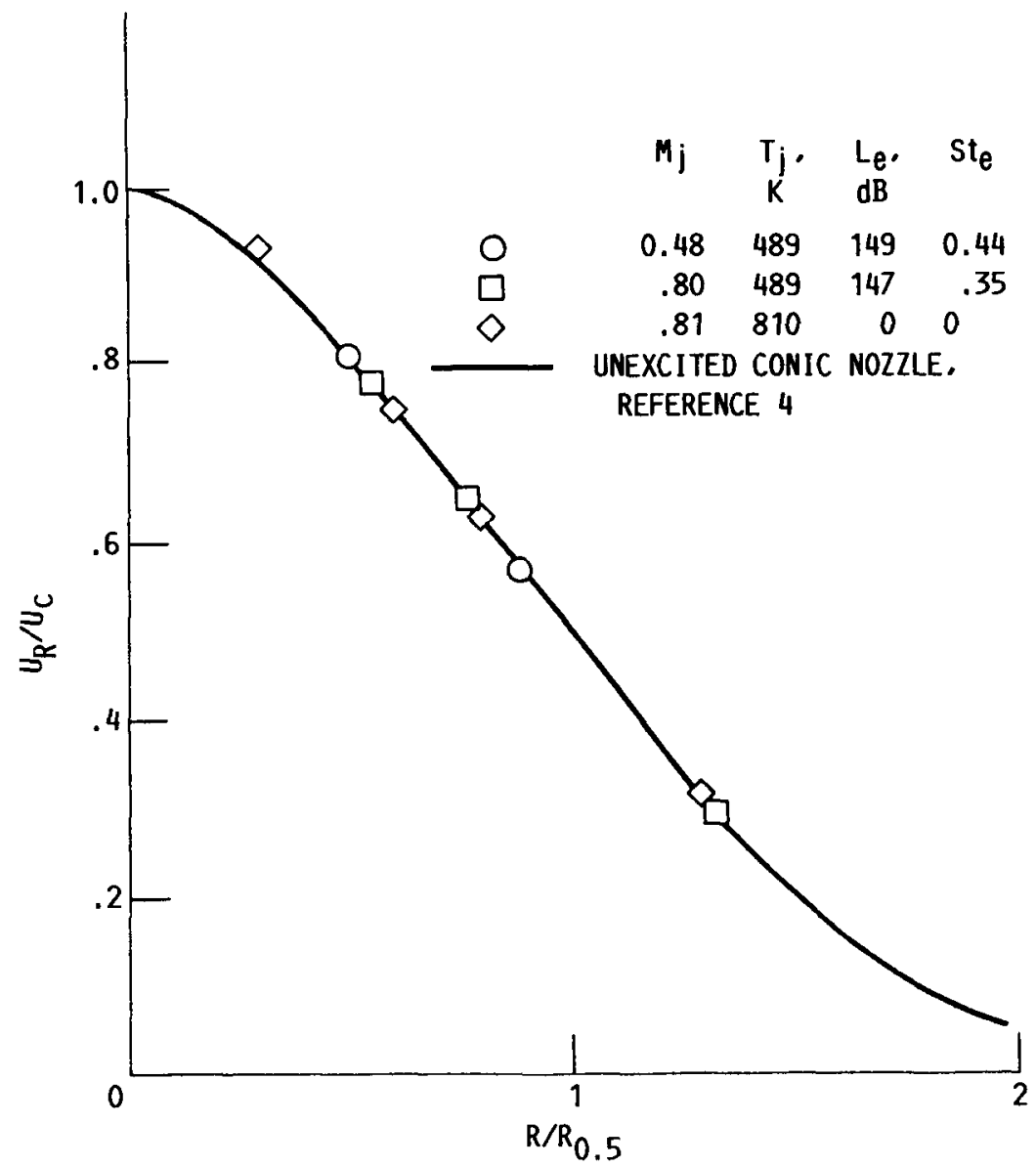

FIGURE 16. - REPRESENTATIVE PLUME RADIAL VELOCITY DECAY WITH AND WITHOUT ACOUSTIC EXCITATION. UNPUBLISHED DATA: $D_{j} \cdot 5.08 \mathrm{cM}: X / D_{j} \cdot 9$ : CONIC NOZZLE. 


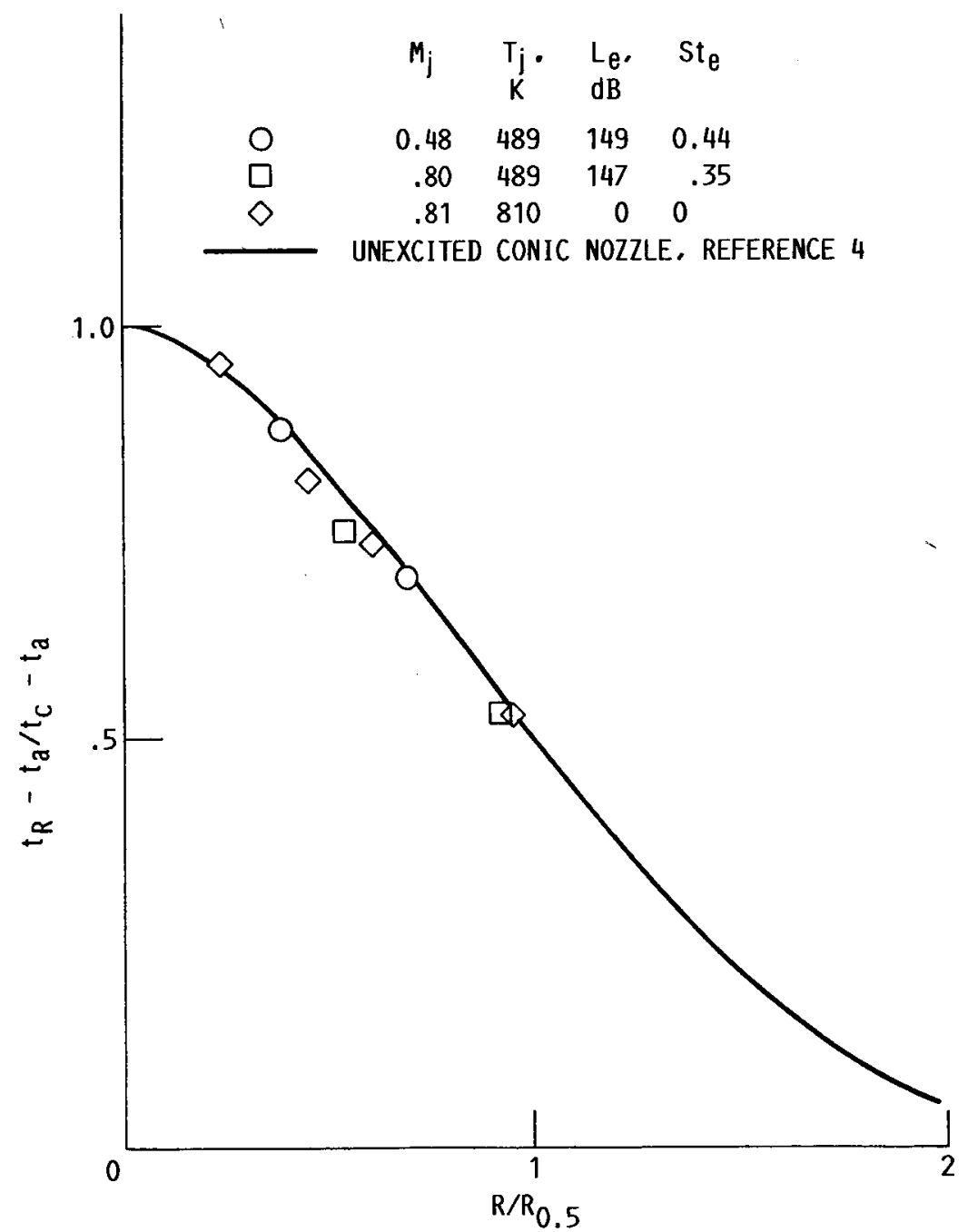

FIGURE 17. - REPRESENTATIVE PLUME RADIAL STATIC TEMPERATURE DECAY WITH AND WITHOUT ACOUSTIC EXCITATION. UNPUBLISHED DATA: CONIC NOZZLE; $\mathrm{D}_{j}, 5.08 \mathrm{~cm} ; \mathrm{X} / \mathrm{D}_{j}, 9$. 


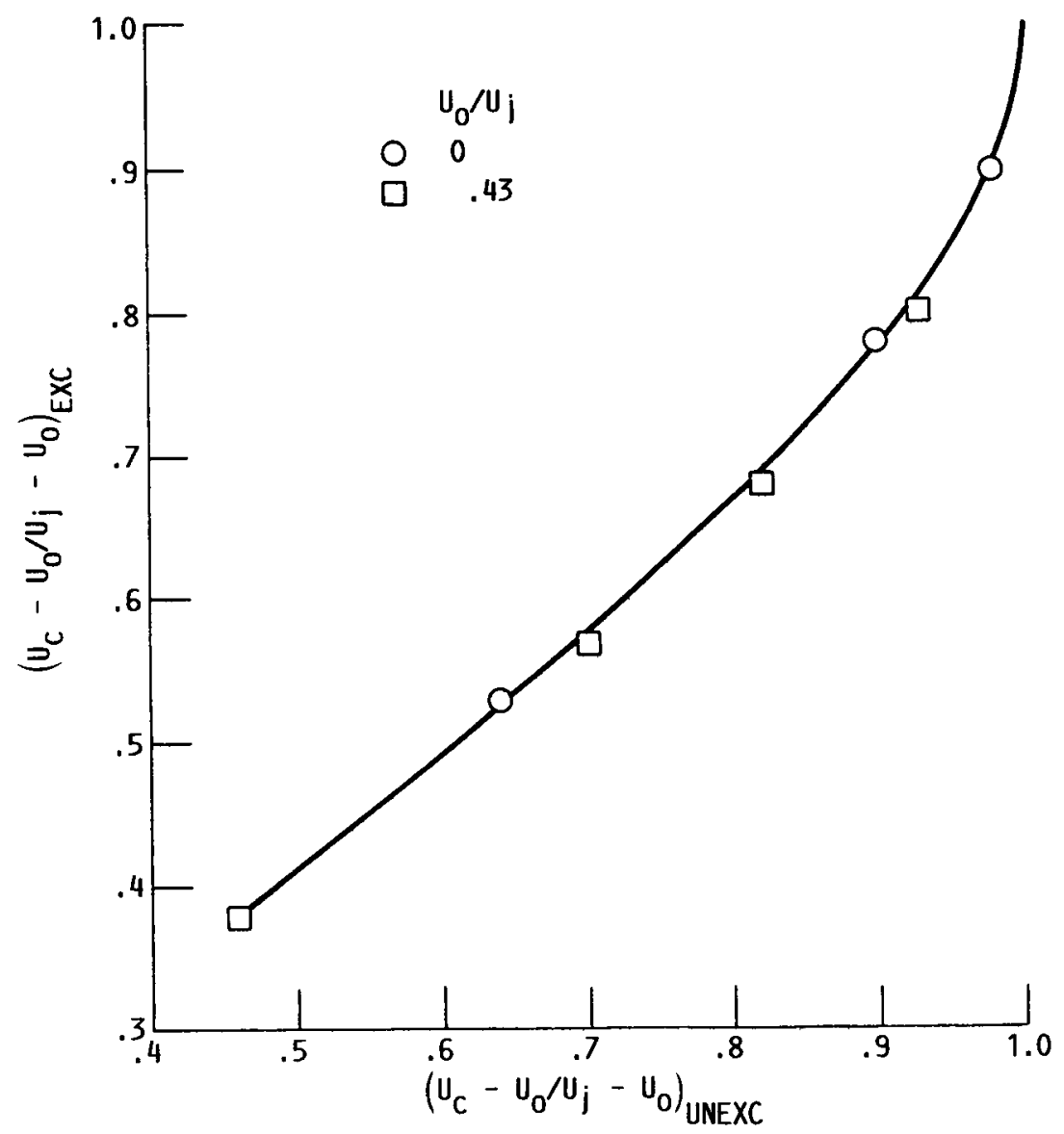

FIgURE 18. - EFFECT OF ACOUSTIC EXCITATION ON PLUME CENTERLINE VELOCITY DECAY WITH AND WITHOUT A SECONDARY STREAM. CONIC NOZZLE; $M_{j}, 0.58$ : EXCITATION LEVEL. $141 \mathrm{~dB}$ : COLD FLOW; REFERENCE 1 DATA. 


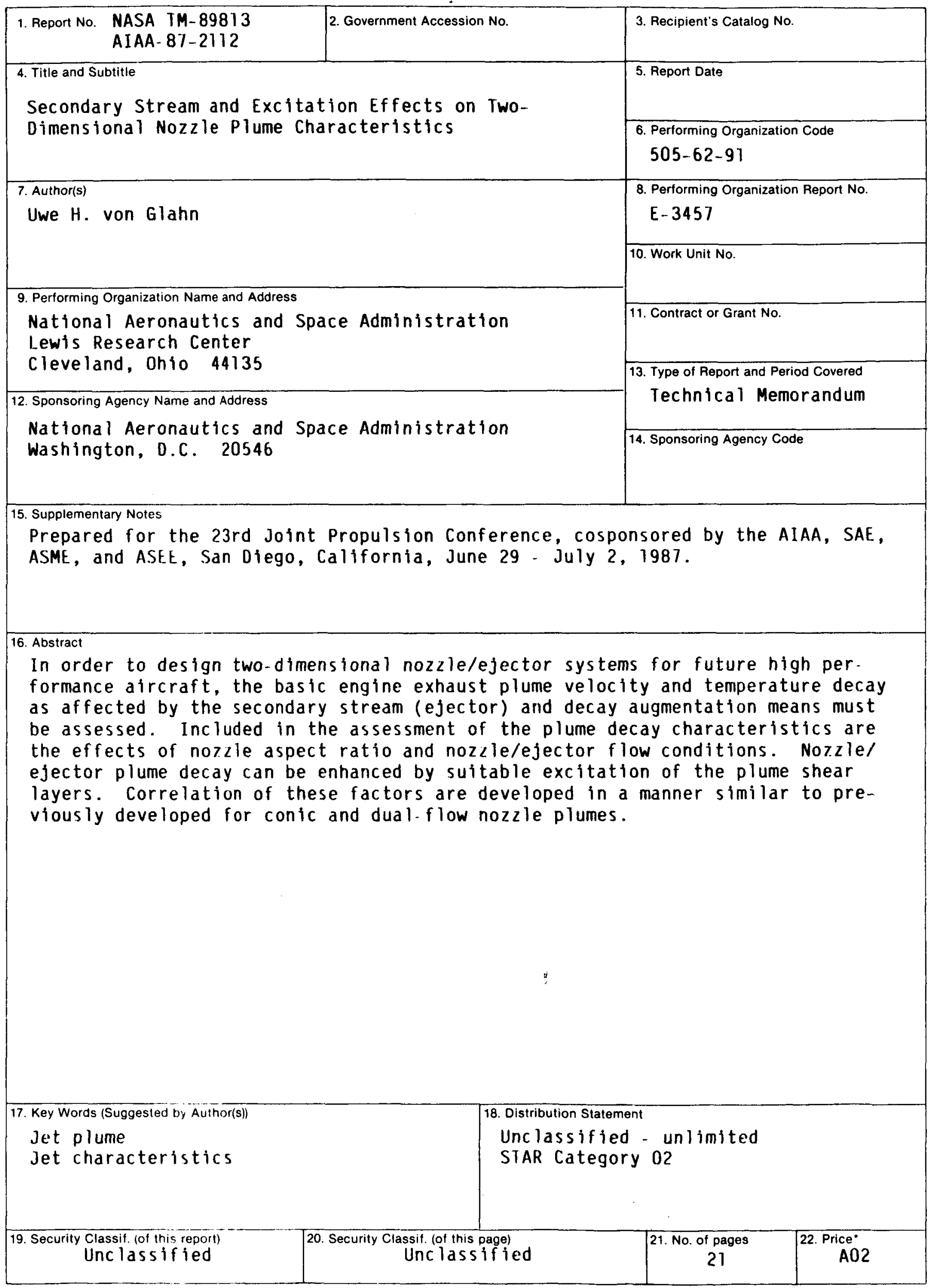

*For sale by the National Technical Information Service, Springfield, Virginia 22161 